\title{
Pharmacovigilance Systems in Arab Countries: Overview of 22 Arab Countries
}

\author{
Thamir M. Alshammari ${ }^{1,2}$ (]) $\cdot$ Neslihan Mendi $^{3} \cdot$ Khalidah A. Alenzi $^{4} \cdot$ Yazed Alsowaida ${ }^{1,5}$
}

Published online: 20 April 2019

○) Springer Nature Switzerland AG 2019

\begin{abstract}
Pharmacovigilance has received much attention in Arab countries recently due to the development of new regulations. However, there are differences in the progression of pharmacovigilance systems by regulatory agencies in these countries because only some are able to meet the requirements for conducting pharmacovigilance activities. Only 45\% of Arab countries are official members of the World Health Organization (WHO) Collaborating Centre for International Drug Monitoring. Countries such as Morocco, Tunisia, Saudi Arabia, Egypt, and Jordan are considered to be advanced pharmacovigilance countries, whereas other countries such as Libya, Yemen, and Palestine remain in the very early stages of implementing and developing pharmacovigilance systems. Countries such as Somalia, Djibouti, Mauritania, and Comoros Island have no pharmacovigilance system or culture. Asian Arab countries have some advantages over those in Africa because $50 \%$ of them are a part of the Gulf Cooperation Council (GCC), meaning that most of them can utilize similar approaches for the application of the majority of activities related to the healthcare system, including pharmacovigilance. Thus, participating in the GCC enables increased connections among these countries. However, one of the strengths in Africa is that Morocco is partnering with the WHO through the WHO Collaborating Center to enhance and strengthen pharmacovigilance across the Eastern Mediterranean Region and the Francophone and Arab countries. This partnership could have a role in enhancing the pharmacovigilance culture among African Arab countries. This review provides a general overview of the current situation regarding regulatory agencies related to pharmacovigilance in Arab countries.
\end{abstract}

\section{Introduction}

Significant development has occurred relating to both the concept and activities of pharmacovigilance over the last two decades in Arab countries. However, notable variations currently exist among the pharmacovigilance systems in Arab countries in terms of their maturity, with some countries having a good pharmacovigilance system that performs

This article was produced as an activity of the International Society of Pharmacovigilance Middle East Chapter.

Thamir M. Alshammari

Thamer.alshammary@gmail.com

Neslihan Mendi

neslihan.mendi@boehringer-ingelheim.com

Khalidah A. Alenzi

ph_kh@hotmail.com

Yazed Alsowaida

ysowaida@gmail.com

1 College of Pharmacy, Department of Clinical Pharmacy, University of Hail, P.O. Box 6166, Hail 81442, Saudi Arabia essential tasks, whereas others do not actually have a pharmacovigilance system [1]. In 2018, $45 \%$ and $31 \%$ of the 22 Arab countries were official and associate members, respectively, of the World Health Organization (WHO) Collaborating Centre for International Drug Monitoring, also known as the WHO-Uppsala Monitoring Centre (WHO-UMC) (Table 1). Five Arab countries are still not members. Furthermore, Arab countries represent only $0.6 \%$ of all reported cases in VigiBase ${ }^{\circledR}$, which included 16,000,000 individual case safety reports (ICSRs) in 2018 [2-4].

2 Medication Safety Research Chair, King Saud University, Riyadh, Saudi Arabia

3 Pharmacovigilance Department, Boehringer-Ingelheim Middle East and North Africa FZ-LLC, Dubai, United Arab Emirates

4 Regional Drug Information Center, Ministry of Health, Tabuk, Saudi Arabia

5 Center for Health Outcomes and PharmacoEconomic Research, College of Pharmacy, University of Arizona, Tucson, AZ, USA 


\section{Key Points}

The complexity and maturity levels of pharmacovigilance systems differ across Arab countries, varying from well-established to poorly established.

In all Arab countries, despite current ongoing activities, further action and initiatives are needed to increase pharmacovigilance awareness among healthcare professionals and consumers.

Despite the existence of the guideline on good pharmacovigilance practices (GVP) for Arab countries, there is still room for the harmonization of pharmacovigilance requirements in Arab countries in terms of resources, health systems, awareness, and applications.

The collaborating center for international drug monitoring established by the WHO in Uppsala, Sweden, the WHO-UMC, is responsible for the technical and operational safety of medications and the processing of the ICSRs in this international pharmacovigilance program. The national pharmacovigilance center or program in each country must meet certain obligations for the country to be a member of the WHO-UMC [5]. To ensure that global data are as up-todate as possible in the WHO-UMC database (VigiBase ${ }^{\circledR}$ ), member countries are required to send ICSRs to the WHOUMC at least every quarter [5]. Because only member countries transmit ICSRs, a full picture of drug safety in all Arab countries is not easily obtained. However, the Arab ICSRs that are sent to the WHO-UMC have better completeness scores, which are calculated based on the provided age at onset, gender, indication, primary reporter, outcome, comments, report type, time to onset, country, and dose $[3,6]$, than those sent by the average country worldwide, making these data more suitable for signal detection.

To achieve the continuous and regular promotion and protection of public health, regulatory authorities worldwide agree and emphasize the importance of effectively communicating the outcome of the pharmacovigilance reviews (i.e., safety reviews) conducted by these regulatory authorities and the decisions made (e.g., label updates). Through the effective communication of safety information, the rational prescription and use of medicines are encouraged, and such communication raises public awareness regarding medicine safety. Therefore, health authorities (HAs) are responsible for establishing effective and solid pharmacovigilance and risk management systems (RMSs) to collect related information from all stakeholders, including healthcare professionals (HCPs), individuals, and pharmaceutical companies. Additionally, to establish consistent and well-defined structured data collection and monitoring systems, the regulator is responsible for enforcing compulsory regulations that aim to achieve proactive risk management and, thus, enhance safety monitoring and reporting [7]. In 1992, Oman was the first Arab country to obtain full membership in the WHOUMC, followed by Tunisia, which became a full member in 1993; in 2018, Syria was the final country to receive full membership (Table 1) [8]. Notable variations exist among the pharmacovigilance systems in Arab countries (Table 2).

\section{Early Initiatives}

Due to the differences among the various populations worldwide (e.g., cultures, diets, ethnicities, etc.) that might affect drug-related reactions (including drug-drug, food-drug, and local remedy-drug reactions), it is very important for countries to establish their own pharmacovigilance systems, which could allow each country to take and request any necessary actions to change medications, such as by using different ingredients, different manufacturing requirements, or imposing certain restrictions/recommendations specific to that country [1]—identifying and addressing barriers to

Table 1 List of Arab countries and their membership status with the World Health Organization (WHO) Collaborating Center for International Drug Monitoring at Uppsala (WHO-UMC) (January 2019) [8]

\begin{tabular}{lll}
\hline Country & Year & Membership type \\
\hline Algeria & 2006 & Associate member \\
Bahrain & 2002 & Associate member \\
Comoro Islands & & No membership \\
Djibouti & & No membership \\
Egypt & 2001 & Full member \\
Iraq & 2010 & Full member \\
Jordan & 2002 & Full member \\
Kuwait & 2018 & Associate member \\
Lebanon & 2018 & Associate member \\
Libya & 2018 & Associate member \\
Mauritania & & No membership \\
Morocco & 1992 & Full member \\
Oman & 1995 & Full member \\
Palestine & & No membership \\
Qatar & 2013 & Associate member \\
Saudi Arabia & 2009 & Full member \\
Somalia & & No membership \\
Sudan & 2008 & Full member \\
Syria & 2018 & Full member \\
Tunisia & 1993 & Full member \\
United Arab Emirates & 2013 & Full member \\
Yemen & 2018 & Associate member \\
\hline
\end{tabular}

The table lists each country's membership status in the WHO program for International Drug Monitoring. (January, 2019) 
Table 2 Summary of the existence of regulations and requirements in Arab countries

\begin{tabular}{|c|c|c|c|c|c|c|}
\hline Country & Regulations & Adverse events & PSUR/PBRER & RMP & QPPV & PSMF \\
\hline Algeria & Yes & $\begin{array}{l}\text { Yes } \\
\text { Serious domestic cases: } 8-15 \mathrm{~cd} \\
\text { Non-serious domestic cases: } 90 \mathrm{~cd} \\
\text { Serious foreign cases: } 8-15 \mathrm{~cd} \\
\text { Non-serious foreign cases: in a PSUR }\end{array}$ & Yes & No & No & No \\
\hline Bahrain & No & NA & NA & NA & NA & NA \\
\hline Comoros & No & NA & NA & NA & NA & NA \\
\hline Djibouti & No & NA & NA & NA & NA & NA \\
\hline Egypt & Yes & $\begin{array}{l}\text { Yes } \\
\text { Serious domestic cases: } 15 \mathrm{~cd} \\
\text { Non-serious domestic cases: } 90 \mathrm{~cd}\end{array}$ & Yes & Yes & Yes & Yes \\
\hline Iraq & Yes & $\begin{array}{l}\text { Yes } \\
\text { Fatal/LT domestic cases: } 15 \mathrm{~cd} \\
\text { Serious domestic cases: } 30 \mathrm{~cd} \\
\text { Non-serious domestic cases: every } 6 \text { months } \\
\text { All foreign cases: } 30 \mathrm{~cd} \text { after request }\end{array}$ & Yes & Yes & Yes & Yes \\
\hline Jordan & Yes & $\begin{array}{l}\text { Yes } \\
\text { Serious domestic cases: } 15 \mathrm{~cd} \\
\text { Non-serious domestic cases: } 90 \mathrm{~cd}\end{array}$ & Yes & Yes & Yes & Yes \\
\hline Kuwait & Yes & $\begin{array}{l}\text { Yes } \\
\text { Serious domestic/foreign cases: } 15 \mathrm{~cd} \\
\text { Non-serious domestic cases: } 90 \mathrm{~cd}\end{array}$ & Yes & Yes & Yes & Yes \\
\hline Lebanon & No & NA & NA & NA & NA & NA \\
\hline Libya & Yes & No specific requirements & $\begin{array}{l}\text { No specific } \\
\text { requirements }\end{array}$ & $\begin{array}{l}\text { No specific } \\
\text { requirements }\end{array}$ & $\begin{array}{l}\text { No specific } \\
\text { requirements }\end{array}$ & $\begin{array}{l}\text { No specific } \\
\text { requirements }\end{array}$ \\
\hline Mauritania & No & NA & NA & NA & NA & NA \\
\hline Morocco & Yes & $\begin{array}{l}\text { Yes } \\
\text { Fatal/LT domestic cases: } 7 \mathrm{~cd} \\
\text { Serious domestic cases: } 15 \mathrm{~cd} \\
\text { Non-serious domestic cases: quarterly }\end{array}$ & Yes & Yes & Yes & No \\
\hline Oman & Yes & $\begin{array}{l}\text { Yes } \\
\text { Serious domestic cases: } 15 \mathrm{~cd} \\
\text { Non-serious domestic cases: } 90 \mathrm{~cd}\end{array}$ & Yes & Yes & Yes & Yes \\
\hline Palestine & Yes & $\begin{array}{l}\text { Yes } \\
\text { Serious domestic cases: } 15 \mathrm{~cd} \\
\text { Non-serious domestic cases: } 90 \mathrm{~cd}\end{array}$ & Yes & Yes & Yes & Yes \\
\hline Qatar & No & NA & NA & NA & NA & NA \\
\hline Saudi Arabia ${ }^{a}$ & Yes & $\begin{array}{l}\text { Yes } \\
\text { Serious domestic/foreign cases: } 15 \mathrm{~cd} \\
\text { Non-serious domestic/foreign cases: } 90 \mathrm{~cd}\end{array}$ & Yes & Yes & Yes & Yes \\
\hline Somalia & No & NA & NA & NA & NA & NA \\
\hline Sudan & Yes & $\begin{array}{l}\text { Yes } \\
\text { No specific requirements }\end{array}$ & No & No & No & No \\
\hline Syria & No & NA & NA & NA & NA & NA \\
\hline Tunisia & Yes & $\begin{array}{l}\text { Yes } \\
\text { Serious domestic cases: } 15 \mathrm{~cd} \\
\text { Non-serious domestic cases: } 90 \mathrm{~cd}\end{array}$ & Yes & Yes & Yes & Yes \\
\hline United Arab Emirates & Yes & $\begin{array}{l}\text { Yes } \\
\text { Serious domestic cases: } 15 \mathrm{~cd} \\
\text { Non-serious domestic cases: } 90 \mathrm{~cd}\end{array}$ & Yes & Yes & Yes & Yes \\
\hline Yemen & Yes & $\begin{array}{l}\text { Yes } \\
\text { No specific requirements }\end{array}$ & Yes & No & Yes & No \\
\hline
\end{tabular}

$C d$ calendar days, ICSRs individual case safety reports, $L T$ life threatening, $N A$ not applicable, $P B R E R$ periodic benefit-risk evaluation report, $P S M F$ pharmacovigilance system master file, $P S U R$ periodic safety update report, $Q P P V$ qualified person for pharmacovigilance, $R M P$ risk management plan, SFDA Saudi Food and Drug Authority

${ }^{a}$ An e-mail was sent by the SFDA suspending the receipt of global (serious and non-serious) ICSRs. Only local (serious and non-serious) ICSRs are required within the same timeframes 
effective pharmacovigilance in clinical practice are imperative for promoting patient safety [9]. Therefore, the League of Arab States (LAS) proposed an important initiative to establish common guidelines regarding several health aspects among Arab nations, such as drug bioequivalence and pharmacovigilance $[10,11]$.

The LAS, which was established in 1945 and initially involved seven countries, currently includes the 22 Arab countries in both Asia and Africa. The LAS includes several sectors that are responsible for enhancing the services available to the population of Arab countries in coordination with the responsible bodies in each country. Health is among the most important facets of the LAS, as demonstrated by efforts to harmonize the guidelines among Arab countries. As a part of the LAS's role in enhancing the health systems in Arab countries, an initiative has been proposed to establish a guideline on good pharmacovigilance practices (GVP) for Arab countries; during the planning stages, the initiative aimed to unify all procedures and activities among Arab countries, but the related activities and procedures were not followed by many countries. The guidelines were adapted from the European Union (EU) GVP. The Arabic Higher Technical Committee for Medicines was established to work on this initiative, and even though the committee included countries from both Asia and Africa, there was no communication between the Asian and African unions regarding the creation of individual medicine agencies (e.g., the African Medicines Agency) [11, 12]. The working groups began in March 2012, and the guidelines were finalized and took effect in July 2015. The guidelines consisted of 532 pages and 15 modules and were supposed to be followed by all Arab countries; however, Saudi Arabia has since published its own pharmacovigilance guidelines, which were also adapted from the EU GVP [11, 13].

Several Arab countries have benefited from the GVP for Arab countries; specifically, some countries, such as Egypt and Jordan, have adopted all of the practices. However, some other countries have only used certain practices, and others have no system for the establishment of pharmacovigilance activities. This review discusses the pharmacovigilance activities in all Arab countries. As all circulars or guidelines are not available on the health authority websites of all countries, some were obtained through direct communication with Iraq, Libya, Morocco, Oman, Palestine and United Arab Emirates (UAE).

\section{Algeria}

\subsection{Background}

After Algeria won its independence from France in 1962, free medical care, particularly for children, elderly individuals, and low-income populations, was introduced in the early 1970s. Subsequently, the healthcare system has improved its structure and services [14].

\subsection{History of Pharmacovigilance}

In 1998, the Centre National de Pharmacovigilance et de Materiovigilance (CNPM) was established under the Ministry of Health $(\mathrm{MOH})$ of Algeria and given financial autonomy. Since 2006, Algeria has been an associate member of the WHO-UMC (Table 1) [8, 15].

\subsection{Pharmacovigilance Regulation in the Country}

The CNPM can receive adverse drug reaction (ADR) reports that are submitted by HCPs and patients/consumers via the CNPM website, whereas marketing authorization holders (MAHs) submit reports via e-mail. Six reports were received in 2010 and 26 reports of adverse reactions were received in 2016 [15, 16]. Although the GVP for Arab countries was published in 2015, the CNPM did not adopt it and instead published its own first pharmacovigilance regulations, but these did not constitute well-defined obligations. In fact, these regulations focused on their main activity of ADR reporting and periodic safety update reports (PSURs) or the new version of PSURs, namely periodic benefit-risk evaluation report (PBRER). Since 27 August 2017, pharmaceutical companies responsible for imported products have been required to submit a PSUR/PBRER using the ICH/ E2C (International Council for Harmonisation of Technical Requirements for Pharmaceuticals for Human Use guideline E2C) format recognized by the WHO every 6 months for the first 2 years and then annually in accordance with the period assigned in accordance with the product's country of reference (Table 2) [15-17].

In addition, the CNPM has made risk communication a priority in their activities. Nonetheless, these regulations require no pharmacovigilance system description, local qualified person for pharmacovigilance (QPPV), or risk management plan (RMP) [15-17].

\section{Bahrain}

\subsection{Background}

The Kingdom of Bahrain is among the eight Gulf Cooperation Council (GCC) countries and is a member of the LAS. Government health services were instituted in Bahrain in 1925, and free medical care and discounted medical expenses have been instituted for Bahrainis and non-Bahrainis, respectively. The Health Improvement Strategy focused on preventive care and improving health via community partnerships to increase awareness about self-care. Another 
pillar of the strategy was to provide evidence-based highquality healthcare consistent with global standards [18].

\subsection{History of Pharmacovigilance}

Several attempts have been made to establish a pharmacovigilance system and start its activities in Bahrain; however, no complete pharmacovigilance system has been established to date. The Kingdom of Bahrain has been an associate member of the WHO-UMC since 2002 (Table 1) [8].

\subsection{Pharmacovigilance Regulations}

In 2013, Bahrain's National Health Regulatory Authority (NHRA) published a document providing guidance for serious adverse event management and provided a reporting form. The NHRA has requested that all healthcare facilities submit serious adverse event reports (SARs) within $48 \mathrm{~h}$. An initial SAR, including all relevant details along with the action(s) taken to minimize the event, should be reported within 7 days, and a full report, including root cause analyses (RCAs) accompanied by action plans to minimize the identified risk, should be submitted to the NHRA within 45 calendar days (Table 2) [19]. To date, no regulations for MAHs have been published.

\section{Comoro Islands}

\subsection{Background}

The Comoro Islands have two major contributors to the provision of health services, creating a disadvantage regarding the harmonization of financial support for the health system: (1) France provides support via a project financed by the French Agency for Development; and (2) Arab countries provide support mainly for the infrastructure of health services. The public sector dominates the provision of hospitals in the Comoro Islands, as demonstrated by the existence of 62 public hospitals and only seven private hospitals in 2014 [20].

In 2015, a new health policy focusing on the introduction of an efficient, high-quality health system accessible to all of the population (particularly those individuals who are in the most need) was adopted [21].

\subsection{History of Pharmacovigilance}

As already mentioned, healthcare provision has not been completely established to date in the Comoro Islands, and, thus, discussing pharmacovigilance is challenging. In fact, there are no pharmacovigilance systems or specific regulations in the Comoro Islands. In addition, the Comoro Islands are not a member of the WHO-UMC [8].

\section{Djibouti}

\subsection{Background}

In Djibouti, health services are dominated by the public sector and are mainly free and relatively accessible to the entire population. However, access to healthcare is much easier in the capital and main district towns than in rural areas that lack a good infrastructure. In the early 1990s, the country survived a civil war and a refugee situation that negatively affected the health system (in terms of healthcare expenditures) and the overall population's health condition. However, since the 1990s, Djibouti has made great efforts to increase health expenditures and, thus, improve the overall health system [22].

\subsection{History of Pharmacovigilance}

Discussing pharmacovigilance in Djibouti is challenging because access to medication is complicated by the challenges faced in the country as mentioned in Sect. 6.1. Therefore, Djibouti has no pharmacovigilance system or specific regulations currently and is not a member of the WHO-UMC $[8,22,23]$.

\section{Egypt}

\subsection{Background}

The healthcare system in Egypt has a vast variety of public and private healthcare providers and financing agents; however, the Ministry of Health and Population (MOHP) is the major healthcare provider in Egypt, particularly of inpatient services. In addition to providing healthcare services, Egypt also has public health programs, such as maternal health and immunization, which aim to improve and create awareness about health in the country. The Egyptian Health Reform Strategy is based on the ability to provide long-term, basic healthcare to all citizens and covers components such as the expansion of social health insurance coverage to whole families and the reorganization of services from a provision perspective with the aim of strengthening the system to ensure the quality of services provided and improve the local pharmaceutical industry [24].

\subsection{History of Pharmacovigilance}

Egypt is considered to be an Arab country with an established pharmacovigilance system and has been a full member of the WHO-UMC since 2001 (Table 1). In 2009, the MOHP established the Egyptian Pharmaceutical Vigilance 
Center (EPVC), and this center has developed and published strong local pharmacovigilance guidelines [25].

\subsection{Adverse Event and Safety-Related Information Collection}

The EPVC is taking all appropriate measures to encourage HCPs to report ADR cases and mandates that pharmaceutical companies collect data regarding the safety and risks of their products in an organized and systemic manner and that they inform the EPVC and patients/consumers about these data and risks. In addition, patients/consumers can submit reports voluntarily $[2,26]$.

The EPVC has started several initiatives, such as the establishment of different types of ADR reporting forms and risk communication avenues. The ADR reporting forms are based on the a color-card reporting system: a yellow card is used to report adverse events and pharmacovigilancerelated problems associated with pharmaceutical products for human use (available in both Arabic and English), a blue card is used to report antiseptic and disinfectant incidents, a pink card is used to report medical device incidents, and a white card is used to report drug quality issues [2, 25, 26]. From its establishment to 2014, the EPVC received approximately 9136 ICSRs, and by 30 August 2018, the center had received 18,346 ICSRs and 4640 RMPs and trained 32,264 HCPs on vigilance, as indicated on the EVPC homepage [26].

\subsection{Pharmacovigilance Regulations}

In 2012, the LAS assigned Egypt to lead the committee responsible for establishing guidelines on GVP for Arab countries, which were completed in March 2014 and became effective on 1 July 2015 [8, 11, 25, 27]. Pharmaceutical companies are required to report both domestic serious and domestic non-serious adverse events to the EPVC through ICSRs as per the E2B guidelines. Foreign cases are followed through periodic reports (i.e., PSURs/PBRERs) (Table 2).

Regarding PSUR/PBRER submissions, the Arab guidelines adopted the same EU GVP submission timelines, and these guidelines have been followed by the EPVC. Similarly, the EPVC requires the submission of an RMP under the following circumstances: new/renewal of product registrations, significant change in the risk/benefit balance, at the request of HAs, and with an application involving a significant change in the existing marketing authorization. The EPVC accepts approved RMPs, but a national version of the RMP should be prepared locally. Furthermore, each pharmaceutical company should have a local QPPV or local safety responsible (LSR) that resides in Egypt and is fully dedicated to his/her job as a QPPV/LSR (Table 2) [11, 25, 28].
As detailed in the guidelines on GVP for Arab countries, the EPVC mandates that pharmaceutical companies functioning in Egypt (generic) have a pharmacovigilance system master file (PSMF). Furthermore, multinational companies should have both a PSMF prepared according to the EU GVP and a national pharmacovigilance subsystem file (national PSSF) describing the key elements of pharmacovigilance activities in Egypt. When the system undergoes a major update, the documents should be submitted to the regulatory authorities. In case the EVPC requests a PSMF to be submitted, it should be received within 14 days.

\section{Iraq}

\subsection{Background}

Currently, Iraq's healthcare services are struggling due to the long period of war and sanctions, which have resulted in the loss of many skilled health workers and new graduates. The national development plans created by the Iraqi $\mathrm{MOH}$ identify primary healthcare as the basis of planned health services. After the implementation of primary healthcare, private healthcare will likely be introduced, but many actions need to be taken before this change can be implemented. Currently, the healthcare system is centralized and mainly focused in hospitals. However, various initiatives aiming to match the needs and locations of healthcare services have been introduced [29].

\subsection{History of Pharmacovigilance}

In 2010, the MOH established the Iraqi Pharmacovigilance Center (IPC), which is under the Department of Technical Affairs Pharmacology, and the IPC became a member of WHO-UMC (Table 1) [8, 30]. Since the establishment of this center, several pharmacovigilance activities, such as ADR reporting and the publication of some circulars and guidelines, have been performed.

\subsection{Adverse Event and Safety-Related Information Collection}

The IPC accepts ADR reports by HCPs, patients/consumers, and pharmaceutical companies [31-33].

\subsection{Pharmacovigilance Regulations}

The "Guidelines for the National Pharmacovigilance System in Iraq" were published in 2012 [31] and directed at HCPs. Furthermore, three circulars targeting MAHs regarding the reporting of safety-related information to the $\mathrm{MOH}$ were published in 2016 and 2017. The IPC has established 
a mixture of regulations based on the EU GVP, guidelines on GVP for Arab countries, and some internal circulars [31-33]. In accordance with the aforementioned circulars, pharmaceutical companies must report both serious and nonserious ADRs. In addition, the guidelines established by the center require the reporting of both domestic and foreign cases, although the reporting timelines for foreign cases differ slightly from those in other countries (Table 2) [33].

The IPC requires pharmaceutical companies (particularly international companies) that already utilize the E2B system to use this system to submit their ADR reports, while the remaining companies (mainly generic companies) must submit their ADR reports using the Council for International Organizations of Medical Sciences (CIOMS) form officially approved by the center [33].

The IPC requires pharmaceutical companies to submit PSURs/PBRERs based on the dates set by the European Medicines Agency (EMA) and within 90 days of the data lock point (DLP). However, when the IPC requests a PSUR/PBRER be submitted, these should be provided within 14 days (Table 2). Similarly, submission of an RMP is required for all pharmaceutical companies that are newly registered, reregistered, and pending registration. An RMP is also required if significant changes are made to a compound, such as the introduction of new uses, the addition of a new age group, or the discovery of new adverse effects or drug interactions [32, 33].

The IPC requests pharmaceutical companies to prepare and approve a PSMF document. This PSMF should be made available upon request by the IPC and should be submitted by the relevant pharmaceutical company within 14 days of the request. In addition, each pharmaceutical company is required to identify an LSR who will carry out all pharmacovigilance activities, and this LSR should be an Iraqi resident (i.e., resides in Iraq) $[32,33]$.

\section{Jordan}

\subsection{Background}

The Jordanian health system is structured into various service providers, including public, private, international and charity sectors, and councils and institutions aiming to develop healthcare. The public sector is formed by the $\mathrm{MOH}$, the Royal Medical Services, and university hospitals. Furthermore, the public sector and charitable sector provide services to Palestinians through United Nations Relief and Work Agency (UNRWA) clinics. The private sector consists of private hospitals and clinics in addition to diagnostic and therapeutic centers [34]. The Jordanian Food and Drug Administration (JFDA), known as the 'FDA' in Arab countries, was established in 2003 and was the first regulatory authority created as a independent body in an Arab country [35].

\subsection{History of Pharmacovigilance}

A pharmacovigilance system was established in Jordan in 2001 before the establishment of the JFDA, and Jordan joined the WHO-UMC in 2002 (Table 1). The JFDA considers pharmacovigilance to be one of its main roles and, thus, restructured the pharmacovigilance center to be under the Rational Drug Use and Pharmacovigilance Department. The Jordan pharmacovigilance center is among the main agencies and plays a major role in the creation of guidelines on GVP for Arab countries. The head of the Jordanian pharmacovigilance center joined the Arab Technical Committee for Medicines in the LAS to review the EMA guidelines and participated in the creation of the new guidelines on GVP for Arab countries [3].

\subsection{Adverse Event and Safety-Related Information Collection}

Since its inception, the Jordanian pharmacovigilance center has introduced several initiatives by publishing its own guidelines and ADR reporting forms, and one of its main strengths is the adoption of pharmacovigilance regional centers. Between 2011 and 2015, five pharmacovigilance regional centers were established in Jordan to increase pharmacovigilance awareness and promote safety reporting [3]. The number of submitted reports has varied over the years, with 42 reports submitted in 2009, 94 reports submitted in 2013, and 180 reports submitted in 2014. Moreover, the yellow card system (reporting form) for reporting ADRs was adopted [1, 2, 27].

\subsection{Pharmacovigilance Regulations}

From 2006 to date, the JFDA has published several pharmacovigilance guidelines. In 2014, a guideline for HCPs was published regarding the detection and reporting of ADRs, and the final guidelines for pharmacovigilance regulation were published in 2016 [2, 3].

The Jordanian pharmacovigilance center uses the same reporting requirements as those used for the type of reports and reporting timelines provided by the new guidelines on GVP for Arab countries. The guidelines on GVP for Arab countries that are adopted in Jordan also specify that the PSMF should always be ready to submit in case it is requested and in case an inspection occurs. In addition, the JFDA requires pharmaceutical companies to have a local QPPV who is responsible for the pharmacovigilance requirements (Table 2) [11].

Pharmaceutical companies must submit an RMP as per the forms and instruction tables adopted by the JFDA in the 
following cases: (1) when submitting a drug registration/ reregistration file or if an already registered drug undergoes the following changes: (a) submitting an application to approve a new indication, and/or (b) applying to add a new age group; (2) if the company has obtained new safety information requiring an emergency management plan during the drug marketing phase; (3) if the company is entitled to apply for an exemption from submitting an RMP, which should include an attachment listing the reasons for this procedure; and (4) product renewal. Additionally, the JFDA can request this form at any time throughout the drug's lifecycle and reserves the right to approve or reject the request. The JFDA requests companies to submit PSURs/PBRERs based on their forms and instructions, and these should be submitted only when the JFDA requests them or when submitting information for drug registration/reregistration, which differs from the guidelines on GVP for Arab countries [36].

\section{Kuwait}

\subsection{Background}

Kuwait's MOH is the major provider of regulations and required healthcare (80\%). A universal health scheme was implemented for local Kuwaitis and expatriates (65\% of the population); however, local Kuwaitis benefit from these schemes more than expatriates because only local Kuwaitis receive free health services, including access to drugs, whereas expatriates are required to pay a fee unless it is an emergency situation [37].

\subsection{History of Pharmacovigilance}

Pharmacovigilance is considered novel in Kuwait and constitutes part of the drug inspection administration of Kuwait Drug and Food Control at the MOH. In 2018, Kuwait joined the WHO-UMC as an associate member (Table 1) [8, 37].

\subsection{Adverse Event and Safety-Related Information Collection}

Although Kuwait is still improving its pharmacovigilance, some good initiatives facilitating pharmacovigilance activities, such as designing an online ADR reporting form to help HCPs report ADRs, have been introduced. Nevertheless, only a very small number of reports have been received over the last two years. In fact, only 212 (14 spontaneous) reports were received in 2016 and 366 (16 spontaneous) reports were received in 2017. On 13 November 2017, the Kuwait $\mathrm{MOH}$ published a circular that encouraged both HCPs and consumers to report ADRs $[8,38,39]$.

\subsection{Pharmacovigilance Regulations}

Kuwait is one of the countries that follow the new guidelines on GVP for Arab countries, but not all pharmacovigilance activities conducted within these guidelines have been followed. As noted earlier, a new circular was published in November 2017 regarding the application of pharmacovigilance in Kuwait, and this circular encouraged both HCPs and consumers to report ADRs.

The preparation and submission requirements of PSURs/ PBRERs follow the same rules as in the new guidelines on GVP for Arab countries and the EU GVP. RMP submission is required under the following circumstances: (1) an EU RMP or a local RMP should be submitted at the time of registering a medicine; and (2) an updated RMP should be submitted at the request of the administration or when there is a significant change to the submitted RMP.

A PSMF is mandatory for pharmaceutical companies functioning in Kuwait, particularly for the new registration of any company. The first submission should include both a global and a local summary. Kuwait does not mandate a QPPV or LSR but encourages pharmaceutical companies to have one. However, there are no specific requirements for the location of the QPPV/LSR (Table 2) [38].

\section{Lebanon}

\subsection{Background}

The healthcare system in Lebanon, specifically healthcare provision and financial aspects of the system, is mainly separated into two categories: public and private. The Lebanese health system has some social coverage because it is based on the principle of solidarity through social security institutions and public sector insurance organizations. Although the Government and its organizations are the main regulators, private healthcare providers play a crucial role in influencing and shaping the market/system. The prices reflect the fact that the private sector meets $90 \%$ of the demand for healthcare. Some laws and regulations regulate health practices, but these regulations are considered weak and insufficient $[40,41]$.

\subsection{History of Pharmacovigilance}

Pharmacovigilance practices in Lebanon are affected by the weak regulations and healthcare system. However, several attempts have been made to establish pharmacovigilance centers since the early 2000s. In 2004, in response to a decree to establish a center to monitor ADRs, a national pharmacovigilance center was launched by the Lebanese University, the main goal of which was to monitor and 
evaluate ADR reports; however, thiswas not successful due to the weak healthcare system.

Despite regulations such as the 2004 decree and the guidelines on GVP for Arab countries, Lebanon lacks many pharmacovigilance activities. However, Lebanon is an associate member of the WHO-UMC, which could aid the establishment of future pharmacovigilance activities (Table 1) [8, 41].

\subsection{Adverse Event and Safety-Related Information Collection}

Although no structured ADR collection and reporting system has been established in Lebanon, ADR reporting occurs via two systems: (1) at the hospital level (each medical file should include ADR reporting forms); and (2) among multinational pharmaceutical companies (which have to report ADRs based on company policies and procedures). However, these two systems are not actually followed in real practice. Moreover, adverse drug event reports are transmitted by some pharmaceutical companies' representatives to their respective scientific bureaus outside Lebanon. Therefore, a comprehensive and well-structured pharmacovigilance program is currently lacking in Lebanon [41, 42].

\section{Libya}

\subsection{Background}

Due to long-lasting wars and disputes, the current healthcare system in Libya is quite insufficient, disorganized, and fragmented. In addition, there is a severe lack of local HCP experts. Therefore, the country has a major problem with patient access to healthcare services [43].

\subsection{History of Pharmacovigilance}

The Libyan $\mathrm{MOH}$ has realized the importance of all pharmacovigilance activities and attempted to implement these activities. However, the obstacles faced by Libya have limited the country's ability to implement and activate pharmacovigilance tools [43, 44]. In 2018, Libya became an associate member of the WHO-UMC (Table 1) [8].

\subsection{Pharmacovigilance Regulations}

On 10 December 2017, the Pharmacovigilance Department of the MOH of Libya published a general request for all pharmaceutical companies to provide pharmacovigilance response details, PSMFs, and PSURs for all products marketed in Libya. Libya follows the guidelines on GVP for Arab countries. However, more effort is needed to ensure the implementation of all pharmacovigilance responsibilities within Libya by both pharmaceutical companies and HCPs (Table 2) [45].

\section{Mauritania}

\subsection{Background}

The health services and medical systems in Mauritania are provided mainly by the $\mathrm{MOH}$. Based on the current health services provided and the existing medical facilities, it can be stated that the Government is not investing enough or as much as other comparable countries into health (currently $7 \%$ ). Although some improvement projects have been initiated, efforts relating to these do not play a very prominent role in the overall health policy. Currently, there are no national regulations or bodies dedicated to checking compliance [46].

\subsection{History of Pharmacovigilance}

Currently, Mauritania has no activities, requirements, or structure related to pharmacovigilance and is not a member of the WHO-UMC [8].

\section{Morocco}

\subsection{Background}

The Moroccan health system is divided into the public and private sectors. The public sector includes the healthcare resources of the MOH, the Royal Armed Forces, local communities, and other ministerial departments. In contrast, the private sector branches into non-profit institutions, including the Mutual and National Fund of Social Welfare Bodies and the National Fund for Social Security. The private for-profit sector also comprises healthcare structures of the free market organized individually or grouped together by HCPs [47].

\subsection{History of Pharmacovigilance}

The Centre Anti Poison et de Pharmacovigilance du Maroc (Anti-poison and Pharmacovigilance Centre of Morocco [CAPM]) was established in 1975 and by 1989 had started to work efficiently with a well-structured organization [48]. The Moroccan MOH has expended extensive effort into organizing its pharmacovigilance system, which is divided into the central, regional, and other levels. The central level includes a national pharmacovigilance committee, the National Pharmacovigilance Center (CNPV), and a National 
Technical Pharmacovigilance Committee (CTPV). Although the CNPV is responsible for pharmacovigilance activities, it does not constitute part of the drug regulatory authority. The role of the national pharmacovigilance committee is to serve as an advisor in the decision-making processes undertaken by the MOH. The main functions of the integrated CNPV include operating the pharmacovigilance system, managing and analyzing adverse events, and ensuring application of the GVP. After analyzing all adverse drug experience (ADE) reports, the CNPV sends these reports to the WHO Collaborating Centre. Additionally, the CNPV participates in investigations, research, HCP training programs, and public awareness. The CTPV is responsible for scientific activities related to pharmacovigilance. At the regional level, the national pharmacovigilance system depends on the choice and selection of a person trained on pharmacovigilance activities who is either a physician or a pharmacist and is responsible for developing these activities in regional and university hospitals [48, 49].

The CAPM is considered one of the centers with GVP among the Arab countries. In 2011, the CAPM became a WHO Collaborating Center for Strengthening Pharmacovigilance Practices to assist the WHO by building capacity in the Eastern Mediterranean, Francophone, and Arab countries. Morocco has been a full member of the WHOUMC since 1992 (Table 1). The center helps and facilitates national training sessions and meetings among the aforementioned regions to promote patient safety. These training sessions have covered several pharmacovigilance subjects, such as causality assessments, pharmacovigilance of herbals, VigiFlow, vaccines, and medication errors [8, 48].

The CAPM is involved in the development of different pharmacovigilance guidelines and methods for minimizing medication errors. In addition, the CAPM has several projects that focus on patient safety reporting systems across health facilities and pharmacovigilance in public health programs, such as tuberculosis (TB) and multidrug resistance to TB treatment $[48,50]$.

In 2013, the CAPM organized the 1st African Congress of Pharmacy, and during the following year it organized the 1st Eastern Mediterranean Region (EMR)/Arab Countries Meeting of Pharmacovigilance (EMR/PV), which aimed to promote principles and collaboration among the EMR and Arab countries. Morocco is considered one of the leading EMR and Arab countries with respect to pharmacovigilance activities [2].

The CAPM is a specialized center that focuses on a wide variety of topics related to patient safety and pharmacovigilance, and some of its other components include phytovigilance, cosmetovigilance, vaccinovigilance, medication errors, and pharmacogenetics. The integration of pharmacovigilance into various health programs, such as the TB control program, parasitosis control program, and trachoma program, allows these programs to decrease the consequences and costs of drugs, reduce failures and resistance to treatment, improve clinical practices, promote the rational use of medicines, and ensure better public confidence in health programs $[48,49,51]$.

In 2000, the CAPM established a center to follow up and monitor the safety of medicinal herbs (pharmacovigilance of herbal medications [phytovigilance]) [48, 49]. Phytovigilance faces many challenges, including the lack of national regulations for medicinal herbals and their poor quality due to counterfeiting and uncontrolled distribution channels through open borders. Only 10\% of these medicinal herbs are registered [52].

\subsection{Adverse Event and Safety-Related Information Collection}

In October 2012, pharmacovigilance was integrated into the Moroccan Tuberculosis Control Program (MTCP). Since the implementation of this program, the average number of spontaneous reports has increased from 3.6 to 37.4 cases per month [50]. Following integration of pharmacovigilance into the MTCP, the program is considered the strongest in this area due to improvements in the management of ADRs and the detection of new signals of antituberculotic and HIV drugs [50, 51].

Physicians and other HCPs are encouraged to report suspected adverse reactions, collect ADE reports, and send these reports to the CNPV. The national pharmacovigilance system in Morocco accepts reports from both HCPs and patients/consumers; these reports are voluntary, and yellow notification forms (paper or online), which can be submitted via the website, telephone (free number available $24 \mathrm{~h}$ a day 7 days a week [24/7]), fax, postal mail, or e-mail, are used for the reporting of spontaneous adverse events [48, 49].

The ICSRs submitted to the WHO global database (VigiBase ${ }^{\circledR}$ ) attest to the growth of the pharmacovigilance program in Morocco. The CNPV has received approximately 23,282 ICSRs since its establishment, and it received approximately 3300 ICSRs in 2017 [53]. The CAPM has performed extensive work on medication errors as it was a coordinating center in a pilot project established by the World Alliance for Patient Safety in collaboration with the WHO-UMC to evaluate the input of pharmacovigilance centers and poison control centers in detecting and evaluating medication errors. The CAPM is considered among the most advanced centers in Africa [51, 54].

\subsection{Pharmacovigilance Regulations}

In 1991, the CAPM published its first circular asking healthcare providers and pharmaceutical companies to report adverse events. In addition to reporting ADRs, local 
regulatory agencies require PSURs/PBRERs to be submitted every 3 months. The CAPM has a mixed system of RMPs because they have adopted the EU RMP system and its requirements and also use some American systems, such as risk evaluation and mitigation strategies. Similar to many other countries, Morocco requires RMPs for new drug applications (including biologics/biosimilars), new safety concerns, any changes in drug indications, or following requests by the CAPM $[47,49,55]$.

\section{Oman}

\subsection{Background}

The health system in Oman, which consists of governmental and private sectors, is unique compared with other systems because it covers both citizens and expatriates working in the public sector. Nevertheless, employers are required to provide private insurance coverage to their employees. The Oman $\mathrm{MOH}$, which is the main healthcare provider, is responsible for ensuring the availability of health policies and plans and for monitoring their implementation. In addition, other sectors, such as the Armed Forces Medical Services and the Royal Oman Police Medical Services, also provide healthcare to their employees [56].

\subsection{History of Pharmacovigilance}

Oman was among the first countries to consider the concept of pharmacovigilance, resulting in its full membership in the WHO-UMC in 1995 [8]. The pharmacovigilance journey in Oman started in 1993, when the country established an infection control section, which was responsible for ADR reporting. A circular directed to HCPs regarding the importance of ADR reporting was issued the following year (1994). In 1994, Oman became an associate member of the WHO-UMC, and within 1 year (1995), it acquired full membership (Table 1). However, due to the low number of reports received at that time, few reports were transferred to VigiBase ${ }^{\circledR}$. Nonetheless, the developmental process of pharmacovigilance has continued to grow in Oman, particularly in 2006. Therefore, a large department called the Department of Pharmacovigilance and Drug Information (DPV\&DI) has been established and is currently responsible for all pharmacovigilance activities in Oman. This department, which is under the Directorate General of Pharmaceutical Affairs and Drug Control of the Oman MOH, involves three sections: (1) pharmacovigilance of human medicines; (2) pharmacovigilance of herbal medicines and health products; and (3) drug information [57].

\subsection{Adverse Event and Safety-Related Information Collection}

Although pharmacovigilance is a broader concept than ADR reporting, the Oman $\mathrm{MOH}$ has exerted extensive efforts to establish a program to increase awareness of ADR reporting, and this program consists of training courses, workshops, and posters. In addition, a pilot study conducted at three tertiary hospitals found that the awareness program played a major role in increasing the number of ADR reports [58, 59]. For reporting communities other than pharmaceutical companies, the DPV\&DI accepts ADR reports from HCPs and consumers/patients, who can submit their reports directly using a simple paper form through the $\mathrm{MOH}$ website or via a smart application [60].

\subsection{Pharmacovigilance Regulations}

In 2017, the DPV\&DI published a concise document entitled the "Guideline on GVP in Oman for MAHs/Pharmaceutical Companies", which was based on three main references: the GVP for Arab countries, EU GVP, and ICH guidelines [60]. The proposed guidelines cover the main modules as reference guidelines and encompass pharmacovigilance quality systems, PSMFs, inspections/audits, RMSs, ICSRs, PSURs/ PBRERs, post-authorization safety studies (PASSs)/postauthorization efficacy studies (PAESs), signal management, and safety communications. A QPPV with a Bachelor's degree in pharmacy or medicine who resides in Oman or another GCC country is required by an entity to ensure that it continues to apply pharmacovigilance activities to maintain the positive benefit-risk work for marketed medications. However, multinational companies with no scientific office in Oman and local pharmaceutical companies are required to have an LSR who resides in Oman. Both the QPPV and LSR should be available 24/7 (Table 2) [57, 60]. Recently, a new circular by the Oman MOH requested that any MAH with ten or more registered medications, i.e., innovators, generics, herbals, and health products, in Oman should have a full-time dedicated LSR residing in Oman. This requirement took effect on 1 January 2019 [61].

Similar to the GVP for Arab countries and the EU GVP, only a summary of the PSMF should be submitted to the DPV\&DI with a marketing authorization application. The location and format are similar to those detailed in the GVP for Arab countries. An EU or core RMP has to be submitted as a part of the RMS and has the same format as the EU GVP. In addition, the EU or core RMP is not required for generic products unless requested by the DPV\&DI. The format, content, and preparation of the PSUR/PBRER follow the EU GVP. Furthermore, the submission timeframe is based on the EU reference list. For all other activities, particularly those associated with PASSs, signal management, 
and safety communications, the concise guidelines follow the EU GVP [60].

As previously mentioned, Oman was among the first Arab countries to start establishing pharmacovigilance, and, despite its slow start, pharmacovigilance activities in Oman have noticeably increased in recent years.

\section{Palestine}

\subsection{Background}

The Palestinian Authority (PA) is responsible for the administration of healthcare through the $\mathrm{MOH}$. In addition to the $\mathrm{MOH}$, healthcare services are provided by other providers, such as the UNRWA, private for-profit providers, and nongovernmental organizations (NGOs), and the private sector plays a strong role in providing healthcare. However, due to resource availability, marked limitations exist in healthcare system practices. Based on data from 2008, there are only 4048 licensed pharmacists and 1000 pharmacy technicians in the West Bank [62-64].

\subsection{History of Pharmacovigilance}

The Medicines Regulatory Authority (MRA) forms a part of the $\mathrm{MOH}$ and plays a role in the establishment of pharmacovigilance systems in Palestine. However, the MRA is currently not a member of the WHO-UMC program [8, 62].

\subsection{Adverse Event and Safety-Related Information Collection}

A previous study found that approximately $47 \%$ of pharmacists believe that they need to report an ADR to the pharmaceutical company and not the authority, indicating that Palestinian pharmacists need intensive training in the area of pharmacovigilance. The public health sector uses the standard form prepared and distributed by the General Directorate of Pharmaceutical Care of the MOH. In addition, no system is currently available for handling risk assessment, risk management, or crisis management, and the medicine regulatory system does not integrate any health programs, e.g., for TB and AIDS [65].

\subsection{Pharmacovigilance Regulations}

On 21 May 2017, pharmacovigilance guidelines were published by the General Directorate of Pharmacy, and these guidelines apply to all healthcare providers, reporters, and MAHs. Any MAH should be represented by a QPPV/LSR, and ADRs should be reported using either the reporting form published by the General Directorate or the company's own form. Companies are also required to submit a PSUR/ PBRER with a product's registration application, and an RMP submission is required with a product's registration application or when there is new safety information requiring the development of an RMP for the respective product. Moreover, according to the guidelines on GVP for Arab countries, companies are requested to prepare local pharmacovigilance system and subsystem master files (Table 2) [66].

\section{Qatar}

\subsection{Background}

The healthcare system in Qatar is a mixed model that combines governmental and private institutions. The Hamad Medical Corporation (HMC), the main healthcare provider, is a non-profit organization supported by the government that covers home care, emergency services, and other services. Free healthcare services are provided to Qatar citizens, who are covered by national health schemes. Non-citizens working in the country should have health insurance provided by their employer [67].

\subsection{History of Pharmacovigilance}

The 2011-2016 National Health Strategy (NHS), a core strategy of which is the safe and effective use of medications, advanced the practice of medication safety and pharmacovigilance in Qatar. This strategy has led to the foundation of the Medication Safety and Quality Center (MSQC) at the HMC. The MSQC has a well-established system for ADR reporting, monitoring, and analysis [68]. Since 2013, Qatar has been an associate member of the WHO Program for International Drug Monitoring, which is coordinated through the Ministry of Public Health (Table 1) [8, 68].

\subsection{Adverse Event and Safety-Related Information Collection}

The pharmacovigilance activities in Qatar are immature, and their focus is currently on ADR reporting and processing, which are usually conducted at major hospitals. All public hospitals have a process for ADR reporting, but this is not the case at private hospitals [69].

\subsection{Pharmacovigilance Regulations}

There is great opportunity for the expansion and development of pharmacovigilance in Qatar [70]. The Pharmacy and Drug Control Department is responsible for medication 
regulations but has not established a pharmacovigilance program to date $[70,71]$.

\section{Saudi Arabia}

\subsection{Background}

The Saudi Food and Drug Authority (SFDA) was established in 2003 as an independent body whose main objectives were to ensure the safety of foods and drugs for humans and animals and the safety of biological and chemical substances and medical devices. The SFDA consists of four main sectors: foods, drugs, medical devices, and operations (inspections are a part of this program) [72]. The Vigilance and Benefit-Risk Assessment (VBRA) executive directorate is located within the drug sector.

\subsection{History of Pharmacovigilance}

Following the thalidomide tragedies, the Saudi MOH has attempted to introduce pharmacovigilance in Saudi Arabia several times, but none of these attempts resulted in the implementation of real pharmacovigilance activities until the establishment of the SFDA. In 2009, the SFDA launched the National Pharmacovigilance Center (NPC) with the aim of monitoring medications to assess their safety profiles and ensure that all medications have a positive benefit-risk profile. Since its establishment, most required pharmacovigilance activities and functions, such as ADR reporting, RMP, PSUR/PBRER, ICSR, signal detection, data mining, and risk communication, are considered to fall within the NPC. The SFDA has supported the NPC and provides all human resources and training required to facilitate its daily work and tasks [71].

In 2009, the year that the NPC was launched, Saudi Arabia became a member of the WHO-UMC after fulfilling all membership requirements and is the 92 nd member among the 134 countries who have full membership in the WHOUMC (Table 1) [8, 71]. The NPC has undergone several developmental processes. After its establishment, a vigilance and crisis management (VICM) executive directorate was established and introduced a medication error department and crisis management; subsequently, the VICM became the VBRA and included a new department, and the organization was modified slightly to match the new structure [71, 72].

\subsection{Adverse Event and Safety-Related Information Collection}

The SFDA accepts ADR and quality defect reports online and in paper form from both HCPs and consumers/patients and makes all forms of communication, such as the internet, mail, e-mail, fax and phone, available. These reports along with other reports from pharmaceutical companies help the VBRA evaluate ADRs and conduct signal detection and data mining to assess the safety of marketed medications. Continuous reviews of drug profiles constitute one of the success stories of the SFDA, which has led to several changes in the safety profiles of drugs due to label changes and even the withdrawal of a harmful drug from the market. These decisions are usually discussed by the pharmacovigilance committee, which is an independent committee comprising pharmacists, physicians, drug safety experts, and epidemiologists [72, 73].

The SFDA is establishing regional pharmacovigilance centers within governmental health institutions whose mission includes protecting patient safety. Furthermore, several training programs for HCPs have been conducted since the establishment of the NPC [72]. A new initiative by the SFDA executive president to reach 30,000 ADR reports in 2018 was launched during the annual celebration meeting of the SFDA. As a part of this initiative, governmental health institutions and private health institutions, including community pharmacies, were targeted to encourage their submission of ADR reports, and the SFDA recently received 47,201 ADR reports [74].

\subsection{Pharmacovigilance Regulations}

In 2015, the SFDA adopted the EU GVP (which was published in 2012) and published the SFDA GVP, which became effective during the same year. Furthermore, because the Saudi GVP and the GVP for Arab countries were both adapted from the EU GVP, they are very similar, with some variation in the ICSR submission requirements, PSUR requirements for generics, and other small differences. Although per regulation, all ICSRs need to be reported, the SFDA has contacted the MAHs via e-mail notifying them that they are suspending the receipt of global ICSRs and that only local (serious and non-serious) ICSRs are required. The PSUR/PBRER submission requirements based on the guidelines are similar to the old method, which is every 6 months for the first 2 years, annually for the next 2 years and then every 3 years thereafter. However, based on personal communication, the SFDA follows the PSUR EU list, which is used by the EU GVP for PSUR submissions. Recently, the SFDA also started to provide a list of medications with their submission date and other information (e.g., DLP). In addition, the Saudi GVP does not require PSURs for generic medications, which is one of the differences between the Saudi GVP and the GVP for Arab countries. Regarding other activities, such as RMPs, PSMFs, and inspections, the SFDA has the same requirements as those detailed in the EU GVP. For instance, a PSMF can be submitted either electronically or in paper format and does not need to be sent 
to the authority unless requested. The SFDA requires pharmaceutical companies to assign a QPPV who should reside in Saudi Arabia and is able to conduct all pharmacovigilance activities (Table 2), and this QPPV can only be a physician or pharmacist $[72,75,76]$.

\section{Somalia}

\subsection{Background}

The health system in Somalia has been affected by the long civil war over the last two decades, which completely disrupted the country. In addition, the country is very poor, and the system is supported by and depends on international agents and institutional donors. However, the Somalian Government recently attempted to boost and enhance its healthcare system $[77,78]$.

Somalia's healthcare system faces many challenges, such as the lack of medications and vaccines, malnutrition, and the spread of epidemic diseases, e.g., measles and cholera. In addition, there is a shortage of health workers [77, 79].

\subsection{History of Pharmacovigilance}

The aforementioned challenges have affected the development of pharmaceutical care in Somalia, particularly a pharmacovigilance system and drug safety monitoring. Hence, to date, Somalia is not a member of the WHO-UMC [8]. The development of Somalian pharmacovigilance needs substantial help from neighboring countries and could benefit from the establishment of harmonized guidelines (i.e., GVP for Arab countries).

\section{Sudan}

\subsection{Background}

Sudan, which is the third largest African country, borders seven countries from Egypt to Ethiopia. Following the Comprehensive Peace Agreement in 2011, South Sudan officially became a separate country with $75 \%$ of the oil reserves, which directly affected the country's revenue. Consequently, the economy and, thus, healthcare suffered. The Sudanese healthcare system currently has three levels: federal, state, and district. The federal level is the general nationwide level, whereas the district level is more specific to various areas in the country. In addition to the healthcare provided at the federal and state levels, the private sector plays a role [80].

\subsection{History of Pharmacovigilance}

Medication safety and pharmacovigilance have existed in Sudan for a long time and have undergone several development phases. The Pharmacy and Poisons Act 1963 led to the development of the Federal Pharmacy and Poison Board (FPPB) in 2001. The role of the FPPB was supervised by the $\mathrm{MOH}$ under the Directorate of General Pharmacy to regulate pharmaceutical affairs and manage the licensing of pharmaceutical facilities. In 2007, the FPPB became the National Medicines and Poisons Board (NMPB), which is currently the executive regulatory body responsible for the legislation, guidelines, and quality of human and veterinary drugs, other aspects involved in the regulation of medications, and the regulation of medical devices [81].

From a drug safety perspective, the NMPB's mission is to ensure that medications are safe and effective. In 2008, Sudan became a full member of the WHO-UMC (Table 1) $[8,81]$. Because Sudan is a full member of the WHO program, the pharmacovigilance tool available for ADR reporting in Sudan is spontaneous reporting through the UMC website [82].

\subsection{Pharmacovigilance Regulations}

In 2009, the NMPB also established a medication error reporting system. Furthermore, an advisory pharmacovigilance committee has had oversight of pharmacovigilance activities since 2012. The NMPB has its own ADR reporting form, and once it receives an ADR report, the NMPB starts to process and analyze the report and provide feedback to the reporter. Between the establishment of the NMPB and 2010, which is the most recent datapoint we were able to obtain, 160 ADR reports have been received. In 2010, the NMPB began to receive RMPs from the MAHs as part of their product submission for authorization [83].

As a part of the NMPB's efforts to enhance ADR reporting, many pharmacovigilance projects, including reporting from national programs for HIV, TB, and malaria (the leading causes of mortality in hospitals in Sudan), and the establishment of a national pharmacovigilance database and guidelines have been initiated [83]. However, more efforts are needed to encourage and motivate HCPs and the public to report ADRs. Furthermore, more education and training for HCPs are required to enhance the culture of pharmacovigilance in Sudan.

MAHs have an obligation to provide a PSUR when registering a product, reporting ADRs, and submitting an RMP; however, there are no specifications. The NMPB has undertaken ongoing development in medication safety and pharmacovigilance by developing guidelines to assist HCPs and pharmaceutical companies (Table 2) [81]. 


\section{Syria}

\subsection{Background}

The healthcare system in Syria is operated by the Syrian $\mathrm{MOH}$, which provides all healthcare services to citizens, including the monitoring of communicable and non-communicable diseases. However, with the current war crisis, many healthcare facilities have been attacked and destroyed, causing millions of Syrian people to use WHO assistance. Furthermore, a group of organizations and HCPs have taken some initiatives to help improve healthcare and healthcare delivery in Syria and have formed the Syrian International Coalition for Health (SICH). All these activities were initiated to help compensate for the weakening of the healthcare system due to the war crisis [84-86].

\subsection{History of Pharmacovigilance}

Before the war crisis, Syria focused on establishing pharmacovigilance activities, which resulted in Syria becoming an associate member of the WHO-UMC in 2012, and Syria received full membership with the WHO-UMC in 2018 (Table 1). Pharmacovigilance in Syria was established in 2011 under the $\mathrm{MOH}$, which has a unit responsible for pharmacovigilance that is locally linked to general hospitals, health programs, pharmaceutical manufacturers, and WHO$\mathrm{UMC}$ at the international level. Pharmacovigilance safety officers are available at hospitals to help with training and education. Nevertheless, these activities might not be active due to the current situation in Syria $[8,87]$.

\section{Tunisia}

\subsection{Background}

Since 1959, the right to free access to health has existed in Tunisia and during this time the healthcare system has faced many challenges and undergone reform many times. In 2016, a social protection system for both public and private sectors was implemented [88].

\subsection{History of Pharmacovigilance}

Tunisia is considered to be among the earliest countries to recognize and implement pharmacovigilance. In 1984, the Ministry of Public Health established a CNPV and placed it under its supervision [89]. The center has undergone several developmental phases and obtained its full functionality when a presidential decree was published in July 1993. The establishment of this center involved three phases. The first phase, which is also known as the transitional phase (1987-1990), consisted of material preparation, structural organization, and experimental operation. This period was followed by the second phase (during the 1990s), which mainly aimed to define the methods, policies, and procedures to be used by the pharmacovigilance center and establish the functional structure. By the end of the 1990s, the third phase, which is known as the operation phase, was initiated. This phase involved the activation of all services provided by the CNPV, which started to receive ADR reports from HCPs and analyze these reports. Tunisia became the 40th member of the WHO-UMC that allowed ADR reporting through the WHO-UMC and has been a full member since 1993 (Table 1) [8, 89].

\subsection{Pharmacovigilance Regulations}

The GVP in Tunisia depends on the GVP for Arab countries and the EU GVP. Therefore, most requirements for ICSRs, including the reporting timeframe, RMPs, PSMFs, and QPPVs, are similar to those described in the GVP for Arab countries. MAHs are required to have pharmacovigilance systems in place and develop PSMFs [90].

An RMP is required for new products marketed in Tunisia if there is a new risk imposed by the drug or there is a significant change in the benefit-risk balance of the drug. The CNPV uses three types of RMP formats: (1) an integrated RMP for medications that do not have a European RMP or other biosimilar medications; (2) a national display of the RMP format to present local and national information regarding medications that have an EU RMP; and (3) an abridged format for generic medicines. As recommended by the GVP for Arab countries, the CNPV receives reports related to any medication that might be associated with an event in all types of populations, and these reports could be submitted by consumers and HCPs via websites or e-mail. Similarly, the CNPV follows the GVP for Arab countries in terms of the reporting timelines. The requirements for PSURs and PBRERs also follow the GVP for Arab countries (Table 2) [89, 90]. The CNPV uses several channels to communicate their safety concerns, e.g., Dear Health Care Professional Letter, newsletters, and a direct question and answer (Q\&A) website for public enquires [89].

\section{United Arab Emirates (UAE)}

\subsection{Background}

The United Arab Emirates (UAE) is among the fastest growing Arab countries with respect to its healthcare system and pharmacovigilance. The Ministry of Health and Prevention (MOHAP) is responsible for operating the healthcare 
system, including pharmacovigilance, in the UAE. Furthermore, national HAs are responsible for the healthcare system in each emirate. The MOHAP operates the healthcare system through the Drug Control Department, which is in the public health policy and licensing sector [91].

\subsection{History of Pharmacovigilance}

Pharmacovigilance has undergone several development phases. Recently, in 2018, the MOHAP and different national HAs agreed on the recommendations from the national pharmacovigilance committee with respect to pharmacovigilance and wrote the "Controls and Requirements of the Good Practices of Pharmacovigilance" [92]. The main objective of this manual is to guarantee patient safety, but it also has other objectives, such as detecting ADRs, monitoring the safety of drugs (particularly high-risk drugs), preventing medication errors, and educating and training HCPs on pharmacovigilance. These objectives also include herbs and supplements $[93,94]$. The UAE has been a full member of the WHO-UMC since 2013 (Table 1) [8].

\subsection{Adverse Event and Safety-Related Information Collection}

The MOHAP receives ADR reports from both HCPs and consumers/patients and allows the submission of these ADR reports through paper forms, e-mails, and smart applications. Pharmacovigilance in the UAE is rapidly growing, and increased efforts are being undertaken to enhance pharmacovigilance among HCPs and the public $[93,94]$.

\subsection{Pharmacovigilance Regulations}

The pharmacovigilance manual or 'guideline' is directed mainly at MAHs who should follow and work according to this guideline with respect to all pharmacovigilance activities and responsibilities. The guideline has many similarities with the EU GVP and GVP for Arab countries because it focuses on the main pharmacovigilance activities, such as PSMFs, RMSs and RMPs, PSURs/PBRERs, ICSRs, and signal detection, risk communication, and QPPV requirements. The MOHAP requires each MAH to have a pharmacovigilance system in place, and each MAH should also have a QPPV who resides in the UAE. International pharmaceutical companies that only have local agents do not need to have a QPPV, but require an LSR who must reside in the UAE (Table 2). The QPPV/LSR should be available 24/7 and, similar to the GVP for Arab countries, the guideline states that the QPPV/LSR should be a pharmacist or physician $[93,94]$.

The requirements for a pharmacovigilance master file and RMS are similar to those stated by the EU GVP; however, the MOHAP requires a National Pharmacovigilance File, which includes additional information, such as reports of ADRs, a risk mitigation plan, PSURs, and training data. In addition to ICSR reporting, any safety information impacting the risk-benefit balance of a product or public health should immediately be reported to the MOHAP. The MOHAP requests MAHs to perform activities related to PSURs/PVRERs, PASSs, and signal detection mainly in accordance with the EU GVP. In addition, similar to the EU GVP and according to the EU list submission timeframes, the UAE requests a PSUR for brand-name medications [93, 94].

\section{Yemen}

\subsection{Background}

Healthcare services in Yemen are provided by the governmental and private sector and are mainly located in main cities. The Ministry of Public Health and Population (MOPHP) operates the healthcare system throughout the whole country [95]. The Yemeni healthcare system has suffered over the last several decades, during which an increasing number of medical facilities have been scattered, causing the system to be close to collapse according to the WHO [96]. Hospitals face a shortage of medical supplies, the spread of epidemic disease, and a lack of operational funds [96], and, according to the MOPHP, 2258 deaths have occurred due to cholera [97].

\subsection{History of Pharmacovigilance}

All medications in Yemen are regulated by the MRA. However, there is not enough legislation for medication regulation and control. A pharmacovigilance center was established in 2011, but the country has neither the structure nor guidelines for the center. To date, Yemen is not a member of the WHO-UMC [8].

\subsection{Adverse Event and Relevant Safety Information Collection}

In 2014, faculties from Aden University introduced an initiative to start a national pharmacovigilance program in Yemen. This program was started by designing an ADR reporting form for HCPs and consumers/patients and creating education materials to enhance the concept of pharmacovigilance among HCPs and the public [95].

\subsection{Pharmacovigilance Regulations}

The aforementioned factors, including the destruction of the infrastructure and the healthcare system, have resulted in the 
lack of mature pharmacovigilance systems and activities in Yemen. However, a circular requiring MAHs to have QPPVs responsible for reporting ICSRs and submitting PSURs was published in 2018 [98]. Therefore, more attention should be focused on enhancing pharmacovigilance activities in Yemen by the LAS and WHO.

\section{Conclusion}

Variations in the maturity of pharmacovigilance systems and activities exist among Arabic countries. Countries such as Morocco, Tunisia, Saudi Arabia, Egypt, and Jordan have a mature pharmacovigilance system. In Morocco, the WHO Collaborating Center is one reason that may explain the very good pharmacovigilance system that has been established, and this center is a success story with respect to pharmacovigilance. Full governmental support and an independent body are the main factors facilitating the establishment of a mature pharmacovigilance system, as observed in various countries, such as Saudi Arabia and Jordan. For instance, the SFDA initiated campaigns to increase awareness regarding the importance of reporting, and within a year approximately 47,000 ADR reports were received from both governmental and private health institutions. Compared with other countries, having a sufficient number of trained personnel has helped countries such as Saudi Arabia and Egypt conduct their pharmacovigilance activities. Other countries, such as the UAE, Iraq, and Oman, are actively pursuing pharmacovigilance and consider it among the top priorities in their health systems. Several barriers, including war, lack of governmental support, and low incomes, have hindered the establishment of a good pharmacovigilance system in other countries. Several African Arab countries, including Somalia, the Comoro Islands, Mauritania, and Libya, lack a pharmacovigilance system due to these barriers. All Asian Arab countries, except for Yemen and Palestine, are either associate or full members of the WHO-UMC, which might indicate that, in contrast to the Arab countries in Africa, Asian Arab countries have the necessary capacity and support to establish a pharmacovigilance system. This might be because most Asian countries, particularly GCC countries, are considered wealthy countries, and their governments support the country's health system, including pharmacovigilance. Increased investment in human resources in these countries and having more specialists in the area of pharmacovigilance might be another reason explaining this difference. Additionally, the establishment of independent bodies such as the SFDA and JFDA could explain the improved pharmacovigilance among Asian countries compared with that in African countries.

Pharmacovigilance is receiving more attention in most Arab countries and has been adopted by many, especially those with a good history of pharmacovigilance applications; however, more effort is needed to help countries whose pharmacovigilance activities are in the early phases.

\section{Compliance with Ethical Standards}

Conflict of interest Thamir Alshammari, Neslihan Mendi, Khaledah Alenazi, and Yazzed Alswaida have no conflicts of interest directly relevant to the content of this review.

Funding No sources of funding were used to assist in the preparation of this review.

\section{References}

1. Wilbur K. Pharmacovigilance in the Middle East: a survey of 13 Arabic-speaking countries. Drug Saf. 2013;36(1):25-30. https:// doi.org/10.1007/s40264-012-0001-y.

2. Bham B. The first Eastern Mediterranean region/Arab countries meeting of pharmacovigilance. Drugs Real World Outcomes. 2015;2(1):111-5. https://doi.org/10.1007/s40801-015-0015-8.

3. Ekelo, M. VigiBase, Global ADR monitoring. The Second Regional Arab Pharmacovigilance Network Meeting; 25 Oct 2017; Riyadh.

4. Vigibase ${ }^{\circledR}$. World Health Organization Collaborating Centre for International Drug Monitoring (Uppsala Monitoring Centre). https://www.who-umc.org/vigibase/vigibase/. Accessed Jul 2018.

5. Being a member of the WHO Programme for International Drug Monitoring. Uppsala Monitoring Center. https://www.who-umc. org/global-pharmacovigilance/who-programme/being-a-membe r/. Accessed Jan 2018.

6. Bergvall T, Noren GN, Lindquist M. vigiGrade: a tool to identify well-documented individual case reports and highlight systematic data quality issues. Drug Saf. 2014;37(1):65-77. https://doi. org/10.1007/s40264-013-0131-x.

7. Al-Essa RK, Al-Rubaie M, Walker S, Salek S. Pharmaceutical regulatory environment: challenges and opportunities in the Gulf region. Basel: Springer International Publishing; 2015.

8. Members of the WHO Programme for International Drug Monitoring. Uppsala Monitoring Centre. https://www.who-umc.org/ global-pharmacovigilance/members/who-programme-membe rs/. Accessed Jan 2018.

9. Stewart D, MacLure K, Paudyal V, Hughes C, Courtenay M, McLay J. Non-medical prescribers and pharmacovigilance: participation, competence and future needs. Int J Clin Pharm. 2013;35(2):268-74. https://doi.org/10.1007/s11096-012-9739-7.

10. Harmonised Arab guideline on bioequivalence of generic pharmaceutical products [in Arabic]. League of Arab States. http:// www.pharmexcil.com/uploadfile/ufiles/HarmonizedArabGuidel inesonBEFinal2014_4may14.pdf. Accessed Jan 2018.

11. League of Arab States. Guideline on good pharmacovigilance practices (GVP) for Arab countries. http://www.jfda.jo/EchoB usV3.0/SystemAssets/PDF/AR/PharmVigilance/TheGoodPha rmacovigilancePracticev2.pdf. Accessed Jan 2018.

12. The League of Arab States [in Arabic]. http://www.lasportal.org/ ar/aboutlas/Pages/HistoricalOverView.aspx. Accessed Dec 2018.

13. Saudi Food and Drug Authority. Guideline on good pharmacovigilance practices (GVP). Drug sector. https://www.sfda.gov.sa/ar/ drug/resources/DocLib2/Guideline\%20on\%20Good\%20Pharmaco vigilance\%20Practices\%20(GVP).pdf. Accessed Jan 2018. 
14. Library Of Congress - Federal Research Division. Country Profile: Algeria. https://www.loc.gov/rr/frd/cs/profiles/Algeria.pdf. Accessed Sept 2018.

15. Republique Algerienne Democratique Et Populaire. Centre National De Pharmacovigilance Et De Matériovigilance [in French]. http://www.cnpm.org.dz/index.php/formations/pharm aco-et-materio.html. Accessed Sept 2018.

16. Algerian Ministry of Health, Population and Hospital Reform. National Center of Pharmacovigilance. Local circular on ICSRs. Note of 20 October 2017. Country Profile: Algeria. May 2008. http://www.rrfa.co.za/wp-content/uploads/2016/01/Alger ia-CNPM-Note-outlining-the-submission-timelines-151206.pdf. Accessed Sept 2018.

17. Algerian Ministry of Health, Population and Hospital Reform. National Agency of Pharmaceutical Products. Local circular on PSUR/PBRER. Note of 27 August 2017. http://www.rrfa.co.za/ wp-content/uploads/2016/01/Algeria-Note-ANPP-27Aug2017Translated.pdf. Accessed on Sep 2018

18. Kingdom of Bahrain. Health improvement strategy 2015-2018. https://www.moh.gov.bh/Content/Files/Health_Improvemen t_Strategy(2015-2018).pdf. Accessed Jan 2018.

19. National Health Regulatory Authority. The NHRA guidance on serious adverse event management and reporting. http:// www.nhra.bh/files/files/Healthcare\%20Facilities/NHRA_Serio us\%20Adverse \%20Events\%20Policy\%20and\%20Reporting.pdf. Accessed Jan 2018

20. World Health Organization. WHO country cooperation strategy at a glance: Comoros. 2016. http://apps.who.int/iris/handle/10665 /137153. Accessed Oct 2018.

21. UNICEF. Comoros. UNICEF annual report 2015. https://www. unicef.org/about/annualreport/files/Comoros_2015_COAR.pdf. Accessed Oct 2018.

22. World Health Organization. Health system profile-Djibouti. http://apps.who.int/medicinedocs/en/d/Js17292e/. Accessed Jan 2018.

23. World Health Organization. Djibouti. Country profile. http://www. who.int/countries/dji/en/. Accessed Jan 2018.

24. Ministry of Health and Population. Egyptian health system and public health. 2018. http://www.mohp.gov.eg/theducation/Secon

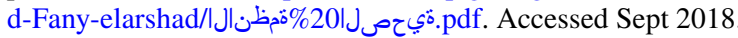

25. The Egyptian Pharmaceutical Vigilance Centre. Guidelines. Ministry of Health and Population. http://www.epvc.gov.eg/guidelines md. Accessed Jan 2018.

26. The Egyptian Pharmaceutical Vigilance Center. http://www.epvc. gov.eg. Accessed Sept 2018.

27. Qato DM. Current state of pharmacovigilance in the Arab and Eastern Mediterranean region: results of a 2015 survey. Int J Pharm Pract. 2018;26(3):210-21. https://doi.org/10.1111/ ijpp.12372.

28. European Medicines Agency. Good pharmacovigilance practices. http://www.ema.europa.eu/ema/index.jsp?curl=pages/regulation /document_listing/document_listing_000345.jsp\&mid=WC0b0

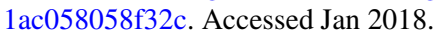

29. Al Hilfi TK, Lafta R, Burnham G. Health services in Iraq. Lancet. 2013;381(9870):939-48. https://doi.org/10.1016/S0140 -6736(13)60320-7.

30. Muhannad S, Adbarwa Y, Jaafer K, Qutaiba A. Assessment of community pharmacists concerning pharmacovigilance in Iraq. Arch Pharm Pract. 2016;7(4):136-41.

31. Iraq Ministry of Health. Guidelines for the Iraqi pharmacovigilance system (IPhvC). 2012. https://www.who-umc.org/media /1078/iraq.pdf. Accessed Sept 2018.

32. Iraq Ministry of Health. Pharmacy section. Iraq PV Center. Circular no DTA/8/9/1, 18/02/2016 (Requested directly from the regulatoryauthority).
33. Iraq Ministry of Health and Environment. Pharmacy Division. Iraq PV Center. Circular no D.A.F/8/9/1/50117, 30/08/2017 (Requested directly from the regulatoryauthority).

34. The Hashemite Kingdom of Jordan, The High Health Council. The national strategy for health sector in Jordan 2015-2019. http:// www.hhc.gov.jo/uploadedimages/The $\% 20$ National $\% 20$ Strategy $\% 20$ for $\% 20$ Health\%20Sector\%20in\%20Jordan\%202015-2019.pdf. Accessed Jan 2018

35. Jordan Food and Drug Administration. About us [in Arabic] http://www.jfda.jo/Pages/viewpage.aspx?pageID=148. Accessed Jan 2018.

36. Bawaresh, N. Jordan Pharmacovigilance System: Past and Future. International Society of Pharmacovigilance Middle East Annual Meeting. (18-19, April 2018). Dubai, United Arab Emirates (Requested directly from the regulatoryauthority).

37. imshealth. Market overview 2016: Kuwait. https://www.tfhc.nl/ wp-content/uploads/2017/08/KLSC-IMS-Kuwait-Health-Indus try-Report-2016-vF2.pdf. Accessed Jan 2018.

38. Al-Essa R. Pharmacovigilance activities in Kuwait. The Second Regional Arab Pharmacovigilance Network Meeting; 25 Oct 2017; Riyadh.

39. Alsaleh FM, Alzaid SW, Abahussain EA, Bayoud T, Lemay J. Knowledge, attitude and practices of pharmacovigilance and adverse drug reaction reporting among pharmacists working in secondary and tertiary governmental hospitals in Kuwait. Saudi Pharm J. 2017;25(6):830-7. https://doi.org/10.1016/j. jsps.2016.12.004.

40. Reindel S, Zucco M. Healthcare in Lebanon. 2010. http://lexar abiae.meyer-reumann.com/blog/2010-2/healthcare-in-lebanon/. Accessed Jan 2018

41. Kassab I. The establishment of an ADR reporting system in Lebanon. The Second Regional Arab Pharmacovigilance Network Meeting; 25 Oct 2017; Riyadh.

42. Hajj A, Hallit S, Ramia E, Salameh P. Order of Pharmacists Scientific Committee-Medication Safety Subcommittee. Medication safety knowledge, attitudes and practices among community pharmacists in Lebanon. Curr Med Res Opin. 2018;34(1):149-56. https://doi.org/10.1080/03007995.2017.1361916.

43. Marschang A, Jaffar S. A briefing on the Libya humanitarian crisis. Surge and Crisis Support, WHO HQ. 2016. https://interagenc ystandingcommittee.org/system/files/libya_presentation_for_iasc_ briefing_health_needs_22_june_2016_am_0.pdf. Accessed Jan 2018.

44. Ministry of Health. Libya. Establishment of pharmacovigilance department (Decree 448) [in Arabic]. 2015. http://www.healt h.gov.ly. Accessed Dec 2018.

45. Ministry of Health. Libya. Pharmacovigilance requirements. Pharmacovigilance department [in Arabic]. 2017. http://www. health.gov.ly. Accessed Dec 2018.

46. Global Centre for Renewal and Guidance. The Mauritanian health care system: overview and recommendations. 2012. http:// diringerassociates.com/wp-content/uploads/2012/06/Mauritania n-Health-System-GCRG-Report-Final.pdf. Accessed Jan 2018.

47. The Global Health Workforce Alliance. Moroccan case study: health care environments in Morocco. https://www.who.int/workf orcealliance/knowledge/PPE_Morocco_CaseStudy.pdf. Accessed Jan 2018.

48. Centre Anti poison et de Pharmacovigilance du Moroc (CAPM) [in French]. http://www.capm.ma. Accessed Aug 2018.

49. Ministry of Health. Kingdom of Morocco. Organisation of the national pharmacovigilance system. 2016. http://www.rrfa.co.za/ wp-content/uploads/2017/01/Morocco-PV-Cirular-n003-Trans lation-160104.pdf. Accessed Aug 2018.

50. Tanani DS, Serragui S, Hammi S, Moussa LA, Soulaymani A, Soulaymani R, et al. National strategy for the 
integration of pharmacovigilance in the Moroccan TB Control Program. Pan Afr Med J. 2017;26:48. https://doi.org/10.11604/ pamj.2017.26.48.7394.

51. Isah AO, Pal SN, Olsson S, Dodoo A, Bencheikh RS. Specific features of medicines safety and pharmacovigilance in Africa. Ther Adv Drug Saf. 2012;3(1):25-34. https://doi.org/10.1177/20420 98611425695.

52. Skalli S, Chebat A, Benkirane R, Soulaymani R. Pharmacovigilance of herbal medicines in Morocco: experience of twelve years, opportunities and challenges. 12th Annual Meeting of the International-Society-of-Pharmacovigilance. Volume 35. https:// www.researchgate.net/publication/295633119_Pharmacovigilan ce_of_Herbal_Medicines_in_Morocco_Experience_of_Twelv e_Years_Opportunities_and_Challenges. Accessed Aug 2018.

53. Alshammari TM, Alqahtani NM, Alenzi KA. Current practices of pharmacovigilance in Middle East: a quantitative study among Arab countries. Pharmacoepidemiol Drug Saf. 2018;27:257-8.

54. Bencheikh RS, Benabdallah G. Medication errors: pharmacovigilance centres in detection and prevention. $\mathrm{Br} \mathrm{J}$ Clin Pharmacol. 2009;67(6):687-90. https://doi.org/10.111 1/j.1365-2125.2009.03426.x.

55. Les Pharmaciens responsables des etablissements pharmaceutiques industriels. Morocco: Ministry of Health. (Requested directly from the regulatoryauthority).

56. Sultanate of Oman, Ministry of Health. Health vision 2050. 2014. https://www.moh.gov.om/documents/16506/119833/Healt $\mathrm{h} \pm$ Vision $\pm 2050 / 7 \mathrm{~b} 6 \mathrm{f} 40 \mathrm{f} 3-8 \mathrm{f} 93-4397-9 \mathrm{fde}-34 \mathrm{e} 04026 \mathrm{~b} 829$. Accessed Aug 2018.

57. Ministry of Health, Sultanate of Oman. Department of Pharmacovigilance and Drug Information. Directorate General of Pharmaceutical Affairs and Drug Control. https://www.moh.gov.om/ en/web/dgpadc/directorates. Accessed Aug 2018.

58. Almaskari MJ, Varughese S. Oman: Oman Pharmacovigilance Centre-the journey [abstract]. 39th Annual Meeting of Representatives of National Pharmacovigilance Centres participating in the WHO Programme for International Drug Monitoring. p. 32. http://www.who.int/medicines/regulation/medicines-safety/ npvc-meeting/Bloolet_poci2016.pdf. Accessed Aug 2018.

59. Almaskari MJ, Varughese S. Oman: change in reporting form format as a means of incorporating other medicine related problems [abstract]. 39th Annual Meeting of Representatives of National Pharmacovigilance Centres participating in the WHO Programme for International Drug Monitoring. p. 13. http://www.who.int/ medicines/regulation/medicines-safety/npvc-meeting/Bloolet_ poci2016.pdf. Accessed Aug 2018.

60. Guideline on Good Pharmacovigilance Practices in Oman for MAHs/ Pharmaceutical Companies. Department of Pharmacovigilance \& Drug Information, DGPA \& DC - MOH, Oman. https://www.moh.gov.om/documents/16539/1767901/Guide line+on+Good+Pharmacovigilance+Practices+in+Oman.pdf/ c5ce6d8b-31b5-4942-ba89-f1c0310951f3. Accessed Aug 2018.

61. Oman Ministry of Health. Directorate of General Pharmaceutical Affairs and Drug Control. Circular no. 50/2018, 20-06-2018 (Requested directly from the regulatory authority).

62. Palestinian National Authority Pharmaceutical country profile. Palestinian Ministry of Health in collaboration with the World Health Organization. http://www.who.int/medicines/areas/coord ination/PalestinePSCP_NARRATIVE-PAL_2011-08-10Final.pdf. Accessed Aug 2018.

63. National Health Accounts 2000-2008, Palestine. https://www. researchgate.net/publication/271832882_National_Health_Accou nts_2000-2008_Palestine/citations. Accessed Aug 2018.

64. World Health Organization. Health conditions in the occupied Palestinian territory, including east Jerusalem, and in the occupied Syrian Golan. http://apps.who.int/gb/ebwha/pdf_files/WHA71/ A71_27-en.pdf. Accessed Aug 2018.
65. Khdour M, Yaghmour N. Pharmacovigilance and adverse drug reactions reporting process in West-Bank, Palestine. Pal Med Pharm J. 2016;1(2):41-8.

66. Palestinian Ministry of Health. General Directorate of Pharmacy. Pharmacovigilance Guidelines Circular. May 21, 2017 (Requested directly from the regulatoryauthority).

67. Goodman A. The development of the Qatar healthcare system: a review of the literature. Int J Clin Med. 2015;6:177-85. https:// doi.org/10.4236/ijcm.2015.63023.

68. Al Hail M, Elkassem W, Hamad A, Abdulrouf P, Thomas B, Stewart D. Overview of pharmacovigilance practices at the largest academic healthcare system in the State of Qatar. Int J Clin Pharm. 2018;40(4):769-74. https://doi.org/10.1007/s11096-018-0629-5.

69. Wilbur K. Pharmacovigilance in Qatar hospitals. Pharm Med. 2012;26:23. https://doi.org/10.1007/BF03256889.

70. Wilbur K. How to improve suspected ADR reporting among pharmacists in the GCC? Saudi Pharm J. 2016;24(6):718-9. https:// doi.org/10.1016/j.jsps.2015.04.005.

71. Wilbur K. Pharmacovigilance in Qatar: a survey of pharmacists. East Mediterr Health J. 2013;19(11):930-5.

72. Alshammari TM, Alshakka M, Aljadhey H. Pharmacovigilance system in Saudi Arabia. Saudi Pharm J. 2017;25(3):299-305. https://doi.org/10.1016/j.jsps.2016.09.008.

73. SFDA. Vigilance and Benefit-Risk Assessment Executive Directorate. https://www.sfda.gov.sa/en/drug/about/sector_departments/ national_pharmacovigilance_center/pages/default.aspx. Accessed Aug 2018.

74. Number of ADR reports at Saudi Food and Drug Authority. https://www.sfda.gov.sa/ar/drug/news/Pages/d8-1-2019a1.aspx. Accessed Jan 2019.

75. Saudi Food \& Drug Authority (SFDA). Guidances. Guideline on good pharmacovigilance practices (GVP) (2015). https://www. sfda.gov.sa/ar/drug/resources/DocLib2/Guideline\%20on\%20Goo d\%20Pharmacovigilance\%20Practices\%20(GVP).pdf. Accessed Aug 2018.

76. List of Saudi reference dates and PSUR submission [in Arabic]. SFDA. https://www.sfda.gov.sa/ar/drug/about/sector_depar tments/national_pharmacovigilance_center/Pages/PSURs.aspx. Accessed Dec 2018.

77. World Health Organization. WHO country cooperation strategy at a glance: Somalia. World Health Organization; 2017. http://www. who.int/iris/handle/10665/136871. Accessed Aug 2018.

78. Warsame A, Handuleh J, Patel P. Prioritization in Somali health system strengthening: a qualitative study. Int Health. 2015;8(3):2014. https://doi.org/10.1093/inthealth/ihv060.

79. UNICEF. Somalia situation report-August-September 2016. https://www.unicef.org/somalia/SOM_sitrep_augsep_2016.pdf. Accessed Aug 2018.

80. Ebrahim EMA, Ghebrehiwot L, Abdalgfar T, Hanafiah Juni M. Health care system in Sudan: review and analysis of strength, weakness, opportunity, and threats (SWOT analysis). Sudan J Med Sci. 2017;12(3):133-50. https://doi.org/10.18502/sjms.v12i3.924.

81. Republic of the Sudan. The National Medicines and Poisons Board [in Arabic]. http://www.nmpb.gov.sd. Accessed Aug 2018.

82. Haleem SEAHA. ABCs of pharmacovigilance in the medical practice. Sudan Med J. 2014;50(3):137-143. http://www.smj. eg.net/journals/pdf/654.pdf. Accessed Aug 2018.

83. The Ministry of Health in collaboration with the World Health Organization. Sudan pharmaceutical country profile (2010). http:// www.who.int/medicines/areas/coordination/sudan_pharmaceut icalprofile_december2010.pdf. Accessed Aug 2018.

84. Ministry of Health. Syrian healthcare system. http://www.moh. gov.sy/Default.aspx ?tabid=246\&language $=$ en-US. Accessed Oct 2018. 
85. Kherallah M, Alahfez T, Sahloul Z, Eddin KD, Jamil G. Heath care in Syria before and during the crisis. Avicenna J Med. 2012;2:51-3.

86. World Health Organization (WHO). Seven years of Syria's health tragedy. http://www.who.int/mediacentre/news/releases/2018/ seven-years-syria/en/. Accessed Oct 2018.

87. Bahnassi A, Al-Harbi F. Syrian pharmacovigilance system: a survey of pharmacists' knowledge, attitudes and practices. East Mediterr Health J. 2018;24(6):569-78. https://doi.org/10.26719 /2018.24.6.569.

88. Fgaier M. The reform of the health care system in Tunisia. Int J Perception Public Health. 2018;2(3):124-7. https://doi. org/10.29251/ijpph.201871.

89. Tunisia. Centre National de Pharmacovigilance [in French]. http:// www.pharmacovigilance.rns.tn/index.php?res $=2$. Accessed Aug 2018.

90. Tunisia. Pharmacovigilance and Risk Management (2016). http:// www.rrfa.co.za/wp-content/uploads/2014/01/Tunisia-PV-Requi rements-IDRAC-152288-160714.pdf. Accessed Aug 2018.

91. United Arab Emirates. Ministry of Health and Prevention. http:// www.mohap.gov.ae/en/Pages/default.aspx. Accessed Aug 2018.

92. Dubai Health Authority web page. https://www.dha.gov.ae/Docum ents/HRD/UAE\%20MOH\%20GVP\%20Guidlines\%202017.pdf.

93. Ministry of Health \& Prevention, UAE. Controls and requirements of the good practices of the pharmacovigilance (2017). http://
www.mohap.gov.ae/en/MediaCenter/News/Pages/1983.aspx. Accessed Aug 2018.

94. UAE MOH Guidelines in Good Vigilance Practice (GVP) for marketing authorization holders/pharmaceutical manufacturers in UAE. Drug Department Public Health Policies and Licensing Sector. Ministry of Health and Prevention UAE. 2018 (Requested directly from the regulatoryauthority).

95. Alshakka A. Pharmacovigilance in Yemen: safety monitoring of medicines: the available mechanism in Yemen. Latvia: Éditions Universitaires Européennes; 2017. https://www.amazon.com/ Pharmacovigilance-Yemen-monitoring-medicines-available/ dp/6202260408

96. WHO. Health system in Yemen close to collapse. http://www.who. int/bulletin/volumes/93/10/15-021015.pdf. Accessed Aug 2018.

97. WHO. Epidemic and pandemic-prone diseases. Outbreak update-cholera in Yemen, 1 March 2018. http://www.emro.who. int/pandemic-epidemic-diseases/cholera/outbreak-update-cholerain-yemen-1-march-2018.html. Accessed Aug 2018.

98. Yemen Ministry of Public Health and Population. Supreme Board of Drugs and Medical Appliances. Circular No. (9/A) of 2018 on the implementation of pharmacovigilance regulation [in Arabic]. http://www.sbd-ye.org. Accessed Jan 2019. 